\title{
On the death of Gerhard König
}

\author{
Gabriele Kaiser $^{1}$
}

Published online: 1 December 2015

(C) FIZ Karlsruhe 2015

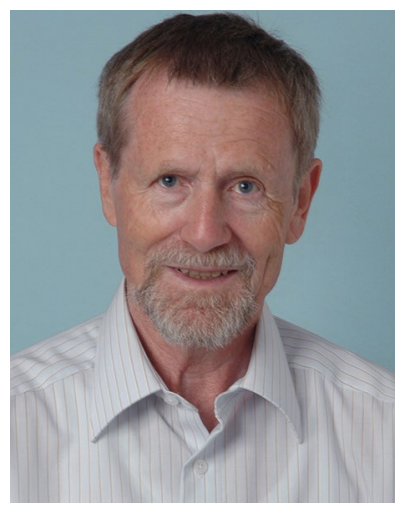

At October 20th, 2015, Gerhard König, the long-time Managing Editor of the ZDM Mathematics Education Journal, passed away. In commemoration of him:

Gerhard König was born on 21 May 1939 in Berlin. He was married and has two children.

After finishing his studies on education, mathematics and physics with excellence at the Free University of Berlin in 1967, Gerhard König worked as editor for mathematics at the publishing house Ernst Klett in Stuttgart. Ernst Klett publisher supported the founding of the Journal „Zentralblatt für Didaktik der Mathematik“ (ZDM) in 1968. ZDM-Zentralblatt für Didaktik der Mathematik was the first name of this journal, which kept the acronym over decades only changing the subtitles. Gerhard König was given the responsibility regarding publishing and the editorial process. The first edition of the ZDM-Zentralblatt für Didaktik der Mathematik was published in June 1969.

Gabriele Kaiser

gabriele.kaiser@uni-hamburg.de

1 Faculty of Education, Mathematics Education, University of Hamburg, Von-Melle-Park 8, 20146 Hamburg, Germany

In 1976, the responsibility for the Journal was delegated to the Zentralstelle für Atomkernenergie-Dokumentation (ZAED), Nuclear Energy Documentation Centre, and later to FIZ Karlsruhe, and on 1 September 1976, Gerhard König became Managing Editor of ZDM and ZAED as well. In October 1978 the journal was taken over by the institution which today is named FIZ Karlsruhe-Leibniz-Institut für Informationsinfrastruktur - the Leibniz Institute for Information Infrastructure.

At the beginning, Gerhard König worked on scientific and organizational tasks in connection with the enlargement of the content of ZDM, and he developed the computer-based input and data processing. Already at an early stage Gerhard König internationalised ZDM, so that since 1978 many non-German publications were included in the data-base on mathematics education. Gerhard König established a co-operation with various national and international institutions. Simultaneously, he supported the transformation of the journal's documentary part into an online database, which at the beginning could be accessed via STN International and later was also accessible as webbased database.

Gerhard König officially represented ZDM at all leading conferences. Thanks to his high dedication and enthusiasm and his excellent leadership, in February 1981 he was appointed as leader of the Mathematics Didactics Group, and January 2001 as Head of the Mathematics Didactics Division.

Apart from his duties at FIZ Karlsruhe, Gerhard König committed himself to teaching and therefore regularly gave lectures on mathematics or accompanied lectures at the University of Karlsruhe.

With his demise, ZDM Mathematics Education lost significant support and assistance. 